\title{
Transitive inference in adults with autism spectrum disorders
}

\author{
Marjorie Solomon • Michael J. Frank • Anne C. Smith • \\ Stanford Ly • Cameron S. Carter
}

Published online: 10 June 2011

(C) Psychonomic Society, Inc. 2011 were largely confirmed. ASDs demonstrated reduced interference from intervening pairs in early training; only TYPs formed a serial position curve by test; and ASDs exhibited impairments on the novel test pair consisting of end items with intact performance on the inner test pair. However, comparable serial position curves formed for both groups by the end of the first block.

Keywords Learning · Generalization · Basal ganglia . Prefrontal cortex $\cdot$ Hippocampus

\section{Introduction}

Autism spectrum disorders (ASDs), which affect at least 1 in 150 individuals (Center for Disease Control and Prevention, 2009), are characterized by deficits in social functioning and language and by the presence of restricted interests and repetitive behaviors. Individuals with ASDs exhibit atypical patterns of learning (Barnes et al., 2008; Mostofsky, Goldberg, Landa, \& Denckla, 2000; Scott-Van Zeeland, Dapretto, Ghahremani, Poldrack, \& Bookheimer, 2010). They show intact (Bowler, Gardiner, \& Grice, 2000; Bowler, Limoges, \& Mottron, 2009; Minshew \& Goldstein, 1993; Salmond et al., 2005) or even superior (Toichi \& Kamio, 2002) semantic memory required for rote learning. However, they demonstrate impairments in more flexible aspects of learning and memory, including the ability to make relational links between individual memory traces that share common elements. This linking is referred to as generalization (Ellenbogen, $\mathrm{Hu}$, Payne, Titone, \& Walker, 2007; Kumaran, Summerfield, Hassabis, \& Maguire, 2009). Generalization of learning from one context to the next is known to be problematic for individuals with ASDs (Stokes \& Baer, 1977), and
A. C. Smith

Department of Anesthesiology and Pain Medicine, University of California, Davis,

Sacramento, CA, USA 
promoting this aspect of learning is a critical goal of virtually all educational and psychosocial interventions for the disorders.

Transitive inference and its mechanisms

One way to assess the ability to flexibly assimilate and/or to transfer what one has learned is through an examination of transitive inference (TI), a form of reasoning that requires training on a hierarchy of stimulus pairs and a transfer of these learned relations to novel pairs at test (Wendelken \& Bunge, 2009). In tasks assessing TI, subjects are trained on successive pairs of stimuli arranged in a hierarchy of $\mathrm{A}+\mathrm{B}-$, $\mathrm{B}+\mathrm{C}-, \mathrm{C}^{+} \mathrm{D}^{-}$, and $\mathrm{D}+\mathrm{E}^{-}$, where + and - indicate reinforced and nonreinforced, respectively. These letters are symbolic representations of the actual characters that may be used. At test, subjects are asked to infer the relations between new items (the BD pair and the much easier AE anchor item pair) on the basis of their training on the hierarchy (Bryant \& Trabasso, 1971; Dusek \& Eichenbaum, 1997; Moses, Villate, Binns, Davidson, \& Ryan, 2008; Piaget \& Inhelder, 1956; Piaget, Inhelder, \& Szeminska, 1960; Vasconcelos, 2008; see Fig. 1a for a pictorial example). TI is demonstrated when a subject can infer that because $\mathrm{B}$ is chosen over $\mathrm{C}$ and $\mathrm{C}$ is chosen over $\mathrm{D}, \mathrm{B}$ should be chosen over $\mathrm{D}$.

TI was considered a test of a high-level logical reasoning ability present only in adult humans until multiple studies showing successful TI in monkeys
(Buckmaster, Eichenbaum, Amaral, Suzuki, \& Rapp, 2004), pigeons (von Fersen, Wynne, Delius, \& Staddon, 1991), rats (Dusek \& Eichenbaum, 1997), and young children (Bryant \& Trabasso, 1971) caused reconsideration of this assumption. Libben and Titone (2008) have articulated two schools of thought about the underlying cognitive mechanisms supporting TI performance. The first, which is referred to as a relational flexibility or conjunctive strategy account, proposes that TI performance relies on successful encoding of the entire stimulus hierarchy, which permits logical interference from learned relational information at the time of testing on novel pairs. Subjects using this more explicit relational strategy are thought to memorize the correct choice of conjunctions of elements (conjunctive representations), which then enables them to successfully complete the task either by comparing $\mathrm{BC}$ or $\mathrm{CD}$ and explicitly inferring that $\mathrm{B}>\mathrm{D}$ or as a result of learning the hierarchy by establishing an ordered relational memory so that $\mathrm{B}$ is already encoded as greater than D. Work in animal models suggests that the hippocampus supports explicit memorization of these conjunctions by binding together their individual elements during early learning (Dusek \& Eichenbaum, 1997; Eichenbaum, 2000, 2004), although the hippocampus may not be required for making the inference itself at test (Frank, Rudy, \& O'Reilly, 2003; Van der Jeugd et al., 2009). Accuracy curves or serial position curves (sequential bar graphs of performance on each pair in the a

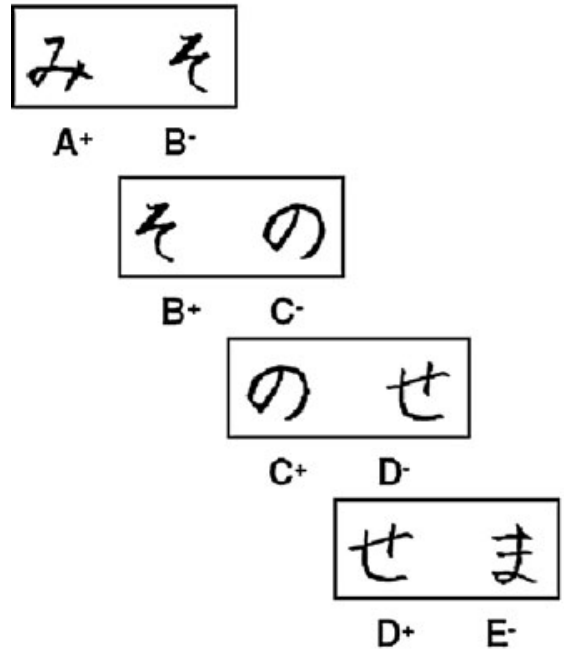

Fig. 1 The TI task. a The four pairs of Japanese hiragana stimuli used in the experiment. Each pair was presented separately on different trials. The hierarchy goes from top to bottom, where the top pair is AB and the bottom pair is DE. In this example, the correct choice is always the stimulus on the left. Note that in actuality, the position of the correct stimulus was randomized across trials, and the assignment of hiragana character to hierarchical element was randomized across b

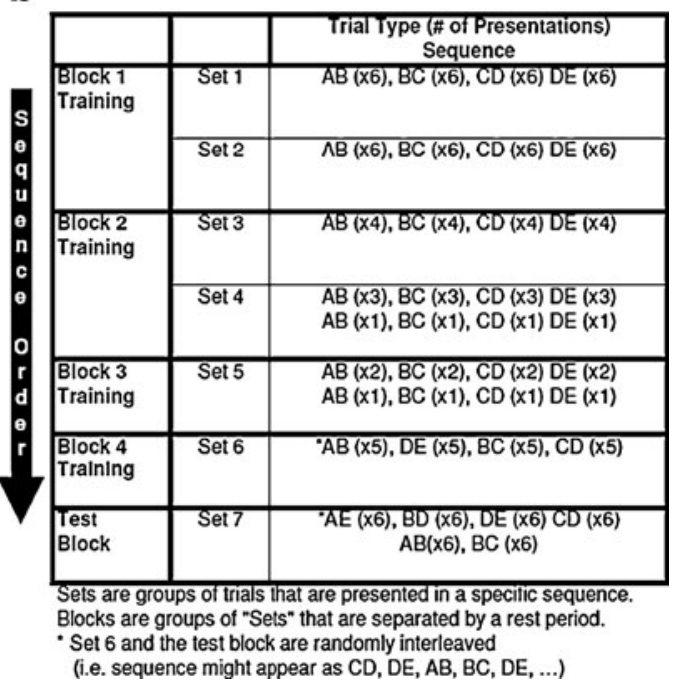

subjects. b The four training blocks of the experiment. In each of the first three blocks, stimuli were presented in sequential blocks of trials of decreasing length. The figure depicts the actual number of trials per set of trials in each block. In set 6 , the stimulus pairs were randomly interleaved (for 20 trials). Subjects had to meet a performance criterion of $67 \%$ on each set before they could advance to the next phase 
hierarchy) produced by this type of relational strategy are relatively flat (i.e., performance is similar for each training pair), since there is less of an associative strength advantage depending on position in the stimulus hierarchy (Vasconcelos, 2008).

The second class of explanations are associative strength or value transfer accounts (Frank, Rudy, Levy, \& O'Reilly, 2005; Frank et al., 2003; Van Elzakker, O'Reilly, \& Rudy, 2003; von Fersen et al., 1991), which have been elaborated and validated through the use of neurocomputational modeling (Frank et al., 2003; O'Reilly \& Rudy, 2001). These suggest that training on a set of consistently reinforced premise pairs results in a graded level of associative strengths among individual stimuli. Anchor pairs $\mathrm{AB}$ and $\mathrm{DE}$ are much easier, given that " $\mathrm{A}$ " is always correct and "E" is never correct. Moreover, even though both "B" and "D" are associated with equal amounts of positive and negative feedback, they develop asymmetrical weights such that " $\mathrm{B}$ " has a positive value and " $\mathrm{D}$ " has a negative one due either to value transfer from $\mathrm{A}$ to $\mathrm{B}$ and $\mathrm{E}$ to D (von Fersen et al., 1991) or to a Rescorla-Wagner blocking effect (Frank et al., 2003). By this account, it is this gradient of unequal associative strengths, and not logical reasoning or relational or conjunctive encoding, that supports transitive interference at test. Over time, accuracy or serial position curves produced by an associative strategy have more of a "U" shape since there are strength advantages for the end anchor pairs that include items that are unambiguously reinforced (Frank, O'Reilly, \& Curran, 2006; Frank et al., 2005; Vasconcelos, 2008).

Formation of this hierarchy of associative weights is thought to be supported by the interworkings of the basal ganglia (Graybiel, 2008; Jog, Kubota, Connolly, Hillegaart, \& Graybiel, 1999), the prefrontal cortex (PFC;Aizenstein et al., 2004; Balleine \& Dickinson, 1998; Daw, Niv, \& Dayan, 2005; Doll, Jacobs, Sanfey, \& Frank, 2009; Graybiel, 2008), and the orbitofrontal cortex (OFC), which is specialized for rapid and flexible updating of representations of expected value and storage of reward-based working memories of stimulus values (Rolls, 2004; Schoenbaum \& Roesch, 2005). The OFC is thought to have the greatest influence on behavior early in learning (Frank \& Claus, 2006), before the influence of the basal ganglia, which are specialized for habit learning (Graybiel, 2008), comes to predominate.

Transitive inference in individuals with ASDs

We hypothesized that individuals with ASDs would exhibit a strategy more consistent with the relational flexibility/ conjunctive account versus one that relied on associative strength/value transfer. This was based on what is known about ASD-related memory impairments and the neuropathology of the disorders, considered in the context of the brain regions and neural circuits thought to support TI, including the hippocampus, basal ganglia, PFC, and OFC (Acuna, Eliassen, Donoghue, \& Sanes, 2002; Greene, Gross, Elsinger, \& Rao, 2006; Heckers, Zalesak, Weiss, Ditman, \& Titone, 2004).

High-functioning individuals with ASDs exhibit intact performance on semantic/rote and familiarity-based memory, and recognition memory (Bennetto, Pennington, \& Rogers, 1996; Beversdorf et al., 2000; Minshew \& Goldstein, 1993; Toichi \& Kamio, 2002), which are thought to rely on medial temporal lobe structures (Squire \& Zola, 1996), although they exhibit impairments on tasks involving memory integration with context (i.e., episodic and recollection memory; Boucher \& Lewis, 1989; Bowler et al., 2000; Toichi \& Kamio, 2003), which are thought to require additional hippocampal and prefrontal mediation (Eichenbaum, Yonelinas, \& Ranganath, 2007).

Autism involves heterogeneous and diffuse neuropathology (Amaral, Schumann, \& Nordahl, 2008); however, the weight of evidence from structural and functional neuroimaging studies suggests that neural circuits involving the $\mathrm{PFC}, \mathrm{OFC}$, and basal ganglia are more impaired than those related to the hippocampus. The first postmortem studies of individuals with autism and mental retardation showed reduced neuronal cell size and increased cell-packing density in the hippocampus (Bauman \& Kemper, 1996, 2005). Several early structural imaging studies (Aylward et al., 1999; Baron-Cohen et al., 2000; Cody, Pelphrey, \& Piven, 2002; Haznedar et al., 2000; Schumann et al., 2004; Sparks et al., 2002) also were consistent with this view, however, others were not (Cody et al., 2002; Palmen, Durston, Nederveen, \& Van Engeland, 2006). Furthermore, newer research and reviews about neuropathology in autism have failed to conclude that the hippocampus is central to the disorders (Amaral et al., 2008; Bachevalier \& Loveland, 2006; Loveland, Bachevalier, Pearson, \& Lane, 2008).

PFC deficits as assessed by behavioral measures of executive control (Pennington \& Ozonoff, 1996; Solomon, Ozonoff, Cummings, \& Carter, 2008), and by neuroimaging studies (Solomon et al., 2009), are more widely recognized. There also is accumulating evidence that OFC structure (Zikopoulos \& Barbas, 2010) and function are atypical in ASDs (Dawson, Hessl, \& Frey, 2008; Girgis et al., 2007; Hardan et al., 2006; Loveland et al., 2008; Schultz et al., 2000) and that the basal ganglia also are atypical with respect to structure (Haznedar et al., 2006; Hollander et al., 2005; Sears et al., 1999), development (Langen et al., 2009), and functional connectivity with other brain regions (Lee et al., 2009; Luna et al., 2002).

The goal of this study was to investigate the generalization of learning in young adults with ASDs versus neurotypical individuals (TYPs) using a TI paradigm. Hypotheses 
were derived from the distinctions drawn by Libben and Titone (2008) between relational flexibility/conjunctive versus associative strength/value transfer accounts of TI. As is summarized in Table 1, each of these strategies produces a different pattern of findings. Our overarching hypothesis was that individuals with ASDs would use a predominantly relational flexibility/conjunctive approach relying more on their strengths in semantic/rote memory, as well as their relative neuropathology of the basal ganglia and $\mathrm{PFC} / \mathrm{OFC}$, and relatively intact medial temporal lobe function. Our first hypothesis was that early learning of the stimulus pairs would be comparable across the groups, since they were easy to memorize, and that both serial position curves would be relatively flat (no differences between inner and outer pairs). Our second hypothesis was that those using a relational strategy and encoding a conjunctive memory for each stimulus pair $\mathrm{AB}, \mathrm{BC}$, and so forth would learn about each pair separately and, therefore, suffer less interference when returning to the $\mathrm{AB}$ pair after having learned that stimulus $\mathrm{B}$ is rewarded when it is paired with $\mathrm{C}$. Thus, we hypothesized that, relative to TYPs, individuals with ASDs would exhibit less reduction in accuracy and shorter RTs during the second presentation of stimuli in the first training block. It also bears mention that this is consistent with findings that involvement of an intact hippocampus is related to the primacy effectthe finding that beginnings of lists are learned better than middle parts (Axmacher, Elger, \& Fell, 2009; Strange, Otten, Josephs, Rugg, \& Dolan, 2002). Third, we hypothesized that the tendency to use a relational versus an associative weight-based strategy would be revealed by the test block in the ASD group. Specifically, we hypothesized that learning of the inner pairs would be comparable across the groups but that the relatively enhanced performance in outer pairs, which is again thought to result from large differences in associative value dependent on basal ganglia/OFC interactions (Frank \& Claus, 2006; Walton, Behrens, Buckley, Rudebeck, \& Rushworth, 2010), would be absent in the ASD group. Fourth, we predicted that performance on the BD pair would be comparable across both groups due to individuals with ASDs' strengths in rote memory of simple conjunctions, but that they would exhibit deficits relative to TYPs in AE performance, which is more difficult when a relational strategy is used.

\section{Method}

\section{Subjects}

Twenty-eight adults with ASDs enrolled in the study; however, 1 was unable to learn the task in the allotted time. This left a final sample size of 27 adults with ASDs (mean age $=23.1$ years, $S D=5.57$ ) and 31 neurotypical adults (mean age $=24.4$ years, $S D=5.08$; see Table 2). On the basis of the male-to-female gender ratio of approximately 4:1 in the population (Nyden, Hjelmquist, $\&$ Gillberg, 2000), 5 women were enrolled in each group. Subjects were recruited through psychiatrists, speech and language pathologists, advocacy groups, psychologists, state-funded centers for persons with developmental disabilities, and M.I.N.D. Institute's Subject Tracking System database. All subjects had a Full Scale IQ of at least 70 on the Wechsler Abbreviated Scales of Intelligence (Wechsler, 1999). Of the 27 enrolled subjects with an ASD, 10 were diagnosed with high-functioning autism, 14 were diagnosed with Asperger syndrome, and 3 with pervasive developmental disorders not otherwise specified, according to criteria set by the Diagnostic and Statistical Manual of Mental Disorders (DSM-IV-TR; American Psychiatric Association, 2000), Autism Diagnostic Observation Schedule (ADOS-G; Lord et al., 2000), and a DSM-IV-TR checklist. The decision to include individuals with both high-functioning autism and Asperger's syndrome derived from studies showing that it is difficult to reliably distinguish between the two disorders (Howlin, 2003; Macintosh \& Dissanayake, 2004; Ozonoff \& Griffith, 2000) and that there is no

Table 1 Hypotheses stemming from each of the two classes of explanations of the mechanisms underlying transitive inference performance as outlined in Libben \& Titone (2008)

\begin{tabular}{|c|c|c|}
\hline & Relational/Conjunctive Strategy & Associative Weight-Based/ Value Transfer Strategy \\
\hline \multirow[t]{2}{*}{ Early training (block 1) } & - Training pairs learned readily & - Training pairs learned readily \\
\hline & $\begin{array}{l}\text { - Flat serial position curve early in learning (first } \\
\text { presentation of training trials) } \\
\text { - Paradoxically less interference from second round } \\
\text { of training pairs }\end{array}$ & $\begin{array}{l}\text { - Formation of serial position curve by the } \\
\text { end of the block }\end{array}$ \\
\hline \multirow[t]{2}{*}{ Test block } & $\begin{array}{l}\text { - Limited formation of serial position curve; no } \\
\text { difference between inner and outer pairs }\end{array}$ & $\begin{array}{l}\text { - Formation of serial position curve; difference } \\
\text { between inner and outer pairs. }\end{array}$ \\
\hline & - Deficit in AE pair at test & - Deficit in BD pair at test \\
\hline
\end{tabular}


Table 2 Subject charactersitics

\begin{tabular}{|c|c|c|c|c|}
\hline & \multicolumn{2}{|c|}{ ASD group $(n=27)$} & \multicolumn{2}{|c|}{ TYP group $(n=31)$} \\
\hline & Mean $(S D)$ & Range & Mean $(S D)$ & Range \\
\hline AGE (Year) & $23.1(5.57)$ & $18-40$ & $24.4(5.08)$ & $18-40$ \\
\hline VIQ & $110.2(16.6)$ & $72-145$ & $112(11.07)$ & $91-128$ \\
\hline PIQ & $107.9(17.43)$ & $73-134$ & $113(13.03)$ & $86-129$ \\
\hline FSIQ & $110.4(17.31)$ & $70-140$ & $115.8(13)$ & $87-136$ \\
\hline ADOS_C & $3.9(1.56)$ & $2-8$ & - & - \\
\hline ADOS_S & $7.3(2.03)$ & $4-12$ & - & - \\
\hline ADOS_R & $1.2(1.04)$ & $0-3$ & - & - \\
\hline ADOS_T & $11.2(3.04)$ & $7-19$ & - & - \\
\hline Total Trials & $197.2(119)$ & $96-480$ & $189.8(147.01)$ & $96-804^{\mathrm{a}}$ \\
\hline
\end{tabular}

empirical distinction in symptomatology and outcome by the time individuals with ASDs reach adolescence (Howlin, 2003; Szatmari, Bryson, Boyle, Streiner, \& Duku, 2003). Exclusion criteria for ASD subjects included diagnoses of autism with known genetic etiologies (i.e., fragile $\mathrm{X}$ syndrome, tuberose sclerosis) and known psychiatric diagnoses. However, assessment with questionnaires after recruitment showed that $37 \%$ of the subjects with ASDs and $6 \%$ of the subjects with typical development met the criteria for attention problems on the Wender Utah Rating Scale (Ward, Wender, \& Reimherr, 1993) and 37\% of the subjects with ASDs and $6 \%$ of the subjects with typical development met the criteria for depression and/or anxiety disorders on the Symptom Checklist -90-Revised (Derogatis, 1994). Subjects taking antipsychotic medications, which are known to interact with the dopamine system, were excluded. Individuals taking stimulants ( 3 in the ASD group) were asked to stop taking these medications for 48 hours prior to the study. Five subjects in the autism group were taking SSRIs, and 2 subjects in the autism group were taking mood stabilizers.

All the subjects gave written assent, along with consent from their legal guardians, to participate in this study, which was approved by the University of California, Davis' Institutional Review Board.

\section{Measures}

To complete learning tasks, subjects were seated in front of a laptop computer with a 15-in. monitor in a lighted room and were asked to view pairs of visual stimuli. Keys on the left and right side of the keyboard were assigned to be "correct" or "incorrect." Visual feedback was provided following each choice as either the word "Correct!" printed in blue or the word "Incorrect" printed in red. If no response was made after $4 \mathrm{~s}$, the words "no response detected" were displayed printed in red.
Transitive inference task (Frank et al., 2005; Frank, Seeberger, \& O’Reilly, 2004)

In the TI task, reinforcement for each pair was deterministic, but stimulus pairs were partially overlapping. Four stimulus pairs were presented such that, symbolically, $\mathrm{A}+\mathrm{B}-$, $\mathrm{B}+\mathrm{C}-, \mathrm{C}+\mathrm{D}-$, and $\mathrm{D}+\mathrm{E}-$ where + and - indicated positive and negative feedback. The actual hierarchy of characters used consisted of Japanese hiragana. During a subsequent test block, the novel combinations $\mathrm{BD}$ and $\mathrm{AE}$ were presented. Training in the TI task consisted of three blocks of trials, followed by a fourth block of randomly interleaved training trials and a fifth test block of randomly interleaved trials. In the first block, stimulus pairs were presented in groupings of 6 trials such that the first grouping consisted of $\mathrm{AB}$ trials, the second grouping consisted of BC trials, and so on. Two such sets were administered. In block 2 , in the first set, groupings were shortened to 4 trials per pair. The next set consisted of four of each trial type, followed by one of each trial type. Block 3 consisted of 4 trials per grouping for the first set and 1 trial per grouping for the second. Block 4 consisted of 5 randomly interleaved trials per grouping. In the test block, all pairs were randomly interleaved for a total of 20 trials before criterion performance was evaluated. However, no feedback was provided during the test block and the two transitive pairs $\mathrm{BD}$ and $\mathrm{AE}$ were added. All pairs were presented 6 times. See Fig. 1b for a schematic diagram of the trial presentation schedule.

\section{Data analysis}

Both univariate and multivariate approaches were used in data analysis because they provide complementary information. Univariate methods provide a more static view of results at given point, whereas multivariate state-space models provide insight into the dynamics of learning over the entire state during which learning occurs. We first examined early learning in block 1 , since this was the time when rapid 
updating of reinforcement contingencies and interference effects would be most evident prior to the consolidation of any hierarchy of associate weights (Frank \& Claus, 2006). Univariate early learning analyses included analyses of variance (ANOVAs) for the first two presentations or sets of trials for the inner $(B C C D)$ versus outer $(A B D E)$ pairs in block 1 to test for the serial position effect. The dependent variables in these analyses were error rates. Second, we employed a Bayesian state-space model to examine the hypothesis that there would be reduced interference in the ASD group on the second presentation or set of trials in the first block. Here, we expected that there would be a difference in the probability that the ASD group versus the TYP group would learn. State-space models work under the assumption that trial-by-trial observations of task performance are a noisy approximation of an underlying smooth cognitive state. Consideration of trial-by-trial performance within the context of this state provides a more accurate means of determining whether learning has occurred than do other methods (A. C. Smith et al., 2004). One question answered by state-space models is whether the probability of a group or subject's performance is above chance on a given trial. Such models can also be used to compare performance between individuals or groups in order to answer the question of whether the performance of one individual or group is different from that of another individual or group. The state-space model can be represented by a state equation and an observation equation (Kitagawa \& Gersch, 1996). The state equation defines the temporal evolution of task learning and is assumed to follow a Gaussian random walk. The observation equation relates the state to the observations using a binomial probability distribution. It is referred to as an ideal observer approach because it computes the learning curve fit to all the data over all time, in contrast to a causal filter approach. The model is estimated using Markov chain Monte Carlo methods (A. C. Smith, Wirth, Suzuki, \& Brown, 2007). Given its sensitivity, this method has become a widely accepted way to conceptualize animal and human learning (e.g., Kumaran et al., 2009; Singer \& Frank, 2009). The state-space model approach computes a smoothed learning curve. Slopes may not be as steep as those of learning curves drawn on the basis of error percentages. To further probe interference effects, we also conducted a $4 \times 2$ ANOVA for reaction times (RTs) during the second set of trials in the first block. Here, we were looking for a slowing in the TYP versus the ASD group.

To investigate the performance of subjects during the test block, we conducted analyses parallel to those used for block 1 (although there was only one set in the test block) and examined overall error rates for inner $(\mathrm{BC} C \mathrm{CD})$ versus outer (AB DE) pairs, using a $2 \times 2$ ANOVA. We also tested this contention with the Bayesian state-space model.
Finally, to examine TI, we used Student's $t$-tests to compare error rates on the novel $\mathrm{BD}$ and $\mathrm{AE}$ pairs across the groups.

All univariate analyses were conducted in SPSS version 18.0. The state-space analyses were performed using Monte Carlo Markov chain software (Lunn, Thomas, Best, \& Spiegelhalter, 2000) interfaced to MATLAB (2009a; The MathWorks, Natick, MA) using MATBUGS (Murphy \& Mahdaviani, 2005).

\section{Results}

\section{Early learning}

A $2 \times 2$ ANOVA testing the serial position effect, using inner versus outer pair as the within-group factor and diagnosis as the between-group factor, revealed no main effect of trial type, $F(1,56)=0.540, p=.466, \eta_{\mathrm{p}}{ }^{2}=.010$, no main effect of group, $F(1,56)=0.336, p=.565, \eta_{\mathrm{p}}{ }^{2}=$ .006 , and no trial type $\times$ group interaction, $F(1,56)=$ $0.756, p=.388, \eta_{\mathrm{p}}{ }^{2}=.013$, during the first presentation of stimulus pairs. This suggests that both groups had flat serial position curves very early in learning. For the second set, however, there was a main effect of trial type, $F(1,56)=15.249, p=.001, \eta_{\mathrm{p}}{ }^{2}=.214$, no effect of group, $F(1,56)=0.030, p=.863, \eta_{\mathrm{p}}{ }^{2}=.001$, and no group $\times$ trial type interaction, $F(1,56)=0.174, p=., \eta_{\mathrm{p}}{ }^{2}=$ .003 . This suggests that both groups started to exhibit the U-shaped serial position curve characteristic of the use of an associative weight-based/value transfer strategy by the end of the first block (see Fig. 2).

To examine our second hypothesis, we applied the Bayesian state-space analysis to each group's pooled responses across the first block of training trials for each stimulus pair (Fig. 3). At each trial, the raw data for the TYP and ASD groups consist of the proportion of correct respondents from that group. The state-space analysis yields median learning curves (the center line) and $95 \%$ credible intervals (the gray bands) for each stimulus trial type. Performance is judged to be above chance for any trial where the $95 \%$ lower credible interval is above .5. Raw data are marked by open circles. This analysis provided mixed support for our second hypothesis that individuals with ASDs would, paradoxically, show less interference on the second round of training trials because they were using a rote memorization versus a relative value encoding strategy. As is shown in Fig. 3, for the $\mathrm{AB}$ trials, both groups performed above chance $(p=.5)$ for at least part of the first 24-trial block. However, for the $\mathrm{AB}$ trials, which initiated the rounds of stimuli, TYPs showed a dip in performance between the first and second rounds of stimulus presentations of this trial type (trial 7). The TYP group showed better performance on $\mathrm{DE}$ trials on the 

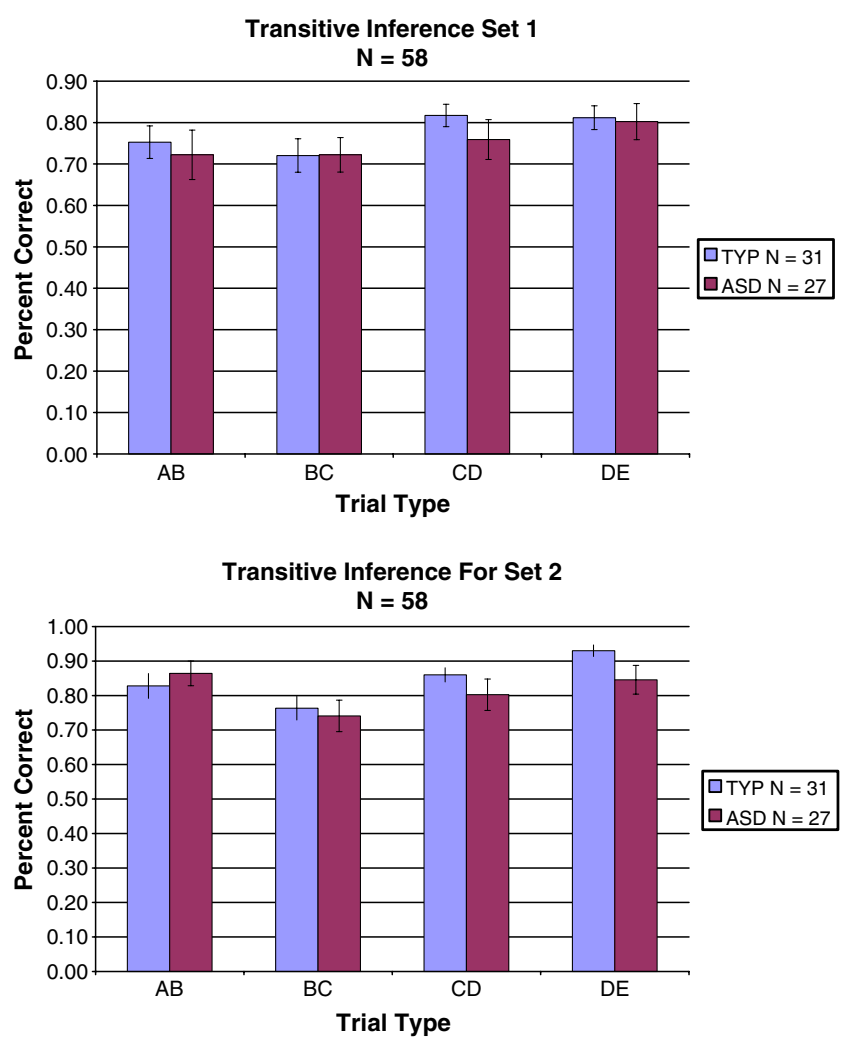

Fig. 2 TI task performance in block 1. Performance of 58 subjects (27 ASDs and 31 TYPs) for sets 1 and 2 during the first block of the TI task

second presentation. In the bottom panel of the figure, we show the trial-by-trial probability that the TYP group's performance was better than the ASD group's performance. This is a probability distribution estimated by subtracting the ASD learning curve distribution from the TYP learning curve distribution. Note that the $95 \%$ credible bounds on this computed difference are broader than the credible intervals on the learning curves, as is expected when subtracting two distributions. These distributions allowed us to estimate when performance between groups was different. From the comparison curves in Fig. 3, it is clear that performance on $\mathrm{AB}$ trials at the beginning of the second round of stimulus pair presentations was worse for the TYP group, consistent with our hypothesis that the ASDs would be less susceptible to interference because they would be more reliant on a rote-memorization-based strategy. This interference effect was not seen for other trial types, although the TYP group performed better on DE trials on the second set. An examination of RTs, using a $4 \times$ 2 ANOVA for trial types during the second set of the first block, showed that, consistent with the premise that they would experience less slowing, the ASD group was quicker than the TYP group on the second set of stimulus pair presentations. Here, RT differences approached significance, $F(1,56)=2.30, p=.135, \eta_{\mathrm{p}}{ }^{2}=.039$. This was driven by the group $\times$ set (first vs. second) interaction for AB trials, $F(1,56)=4.35, p=.038, \eta_{\mathrm{p}}^{2}=.075$.

Test block

A $2 \times 2$ ANOVA with trial type (inner vs. outer) as the within-group factor and diagnostic group (ASD and TYP) as the between-group factor was used to test for group differences in the serial position effect. The main effect of trial type (inner vs. outer) was not significant, $F(1,56)=$ 2.45, $p=.123, \eta_{\mathrm{p}}^{2}=.042$, and neither was the effect of group, $F(1,56)=2.06, p=.16, \eta_{\mathrm{p}}^{2}=.035$. However, the interaction of inner and outer pairs by group was significant, $F(1,56)=3.98, p=.050, \eta_{\mathrm{p}}{ }^{2}=.07$. Planned comparisons showed that there was a significant difference between the ASD and TYP groups on error rates for the outer, but not the inner, pairs, $t(56)=2.25, p=.031$ (see Fig. 4). This suggested that although neither group showed a pronounced inner versus outer pair difference at test, the ASD group showed a flatter curve and less advantage for end item pairs than did the TYP group. The Bayesian statespace model also confirmed this pattern of inner versus outer pair results.

As is shown in Fig. 5, Student's $t$-tests were used to examine group differences between error rates on $\mathrm{BD}$ and AE pairs. There was no significant group difference in performance on the BD pair, which is considered to be the classic pair where TI is seen. However, as was hypothesized, the group with ASDs did perform significantly worse on the AE pair, $t(56)=2.843, \quad p=.007$.

\section{Discussion}

Our overarching contention that high-functioning young adults with ASDs would exhibit performance on a TI task that was more consistent with a relational flexibility strategy reliant on rote memory versus a relative value encoding strategy based on reinforcement-driven representation was largely confirmed. Consistent with our hypotheses, neither group showed a strong serial position effect across the first set of training pairs. The TYP group showed the predicted dip in performance on the second round of $\mathrm{AB}$ trials, whereas the ASD group showed continuous improvement on this second presentation, providing support for reduced interference. The TYP group also showed better performance on the outer DE pair on the second set, supportive of the premise that they were better at end item pairs that relied more on accrual of associative strength. By the test block, individuals with ASDs exhibited reduced learning of the outer pairs and a consequent flattened Ucurve, consistent with having employed a conjunctive, rather than an associative, strategy. Notably this pattern is 


\section{Stimulus $A>B$}

Typical $n=31$

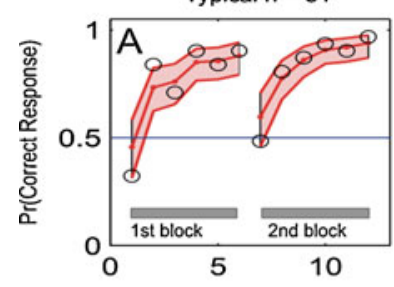

ASD $n=27$
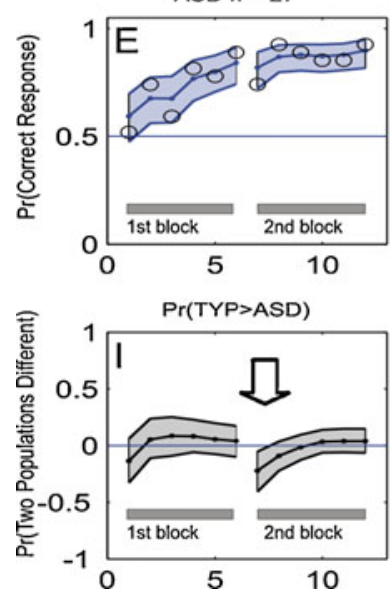

$\mathrm{B}>\mathrm{C}$

Typical $n=31$

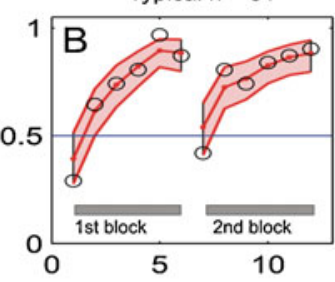

ASD $n=27$
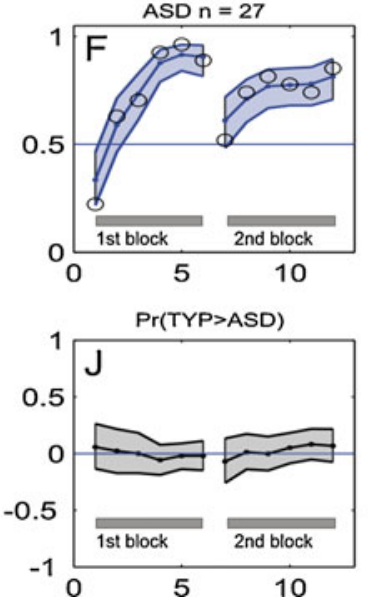

Fig. 3 A state-space model of TI performance in block 1. The statespace model showing the performance on allthe trial types for 58 subjects (27 ASDs and 31 TYPs) during the first two sets (12 trials). For the AB trials, ASDs show a gradual increase in performance as the

opposite to that seen following lesions of the hippocampus in rodents (Van der Jeugd et al., 2009) or pharmacological manipulations in humans that target this system (Frank \& O'Reilly, 2006). Hypotheses of spared BD performance and impaired $\mathrm{AE}$ performance were confirmed, suggesting that individuals with ASDs did not build an extensive associative value hierarchy that would have made the $\mathrm{AE}$ pair trivial. Contrary to our predictions, across the first and second sets of trials making up the first training block, both groups exhibited similar performance, consistent with the gradual development of the serial position effect, although this was no longer present for the ASD group by the test block.

While we adopted a focus on relational/conjunctive versus associative weight based/value transfer approaches, in practice, many individuals adopt a combination of different strategies for TI, with the balance of strategies used depending on such factors as age, verbal abilities, overall cognitive abilities, semantic relationships between stimulus items, and explicit awareness of the hierarchy (Moses, Ostreicher, \& Ryan, 2010). The lack of complete consistency in our findings may be a result of noise induced by strategy differences within and between the groups. Individual differences in approaches used to complete TI
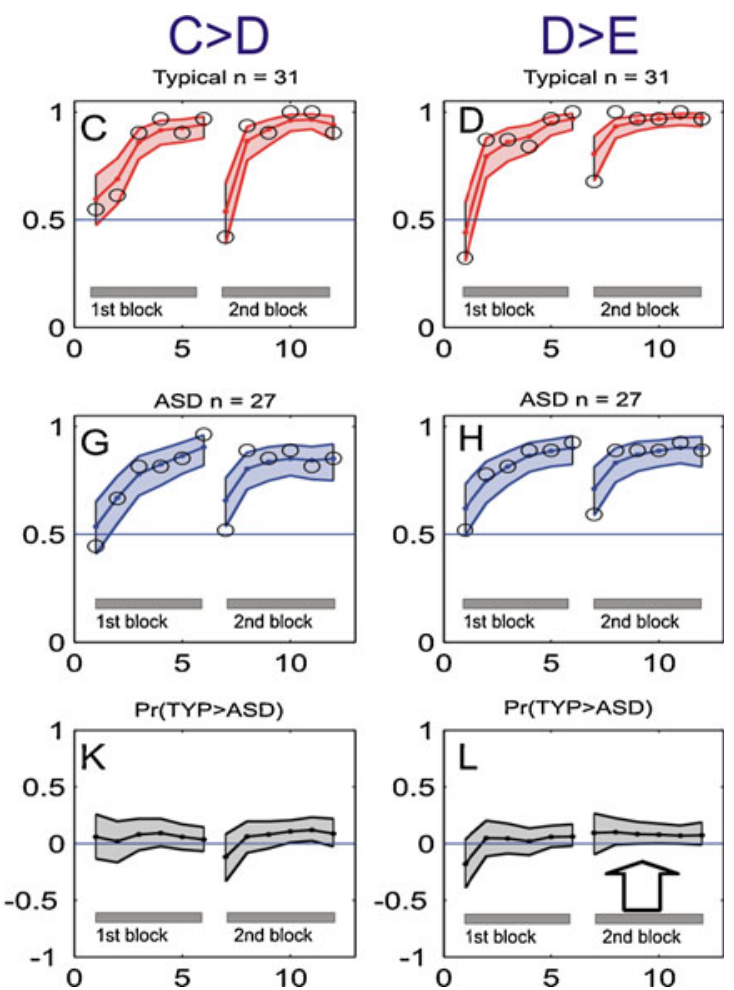

task progresses, but TYPs show a dip in performance when the trials are repeated (trial 7). There is a significant differenceon trial 7 between groups on the AB trials. For the TYP group, DE trial performance was superior on the second set

may be especially relevant for individuals with ASDs, who are known to use alternative strategies, relative to TYPs, in other types of tasks (e.g., Dapretto et al., 2006; Koshino et al., 2005; Pelphrey, Morris, \& McCarthy, 2005). Future studies investigating the presence and impact of such strategy differences may help shed light on our findings and their impact on the daily functioning of individuals with ASDs.

Hypothesized findings of an AE pair impairment are striking. The AE pair generally is considered trivial, as evidenced by the fact that performance of the TYP individuals in our study was close to $100 \%$, as is commonly the case. Impaired performance on this relatively easier pair in the context of intact performance on the relatively more difficult BD pair constitutes evidence that our findings are not merely due to a generalized performance deficit in patients. It also is interesting to note that in other patient populations, such as adults with schizophrenia, the pattern of findings is reversed, with intact $\mathrm{AE}$ performance and impaired $\mathrm{BD}$ pair performance on a four-pair TI task (Coleman et al., 2010; Titone, Ditman, Holzman, Eichenbaum, \& Levy, 2004). These findings in schizophrenia are taken as evidence of deficits in hippocampallymediated relational binding, providing indirect support for 

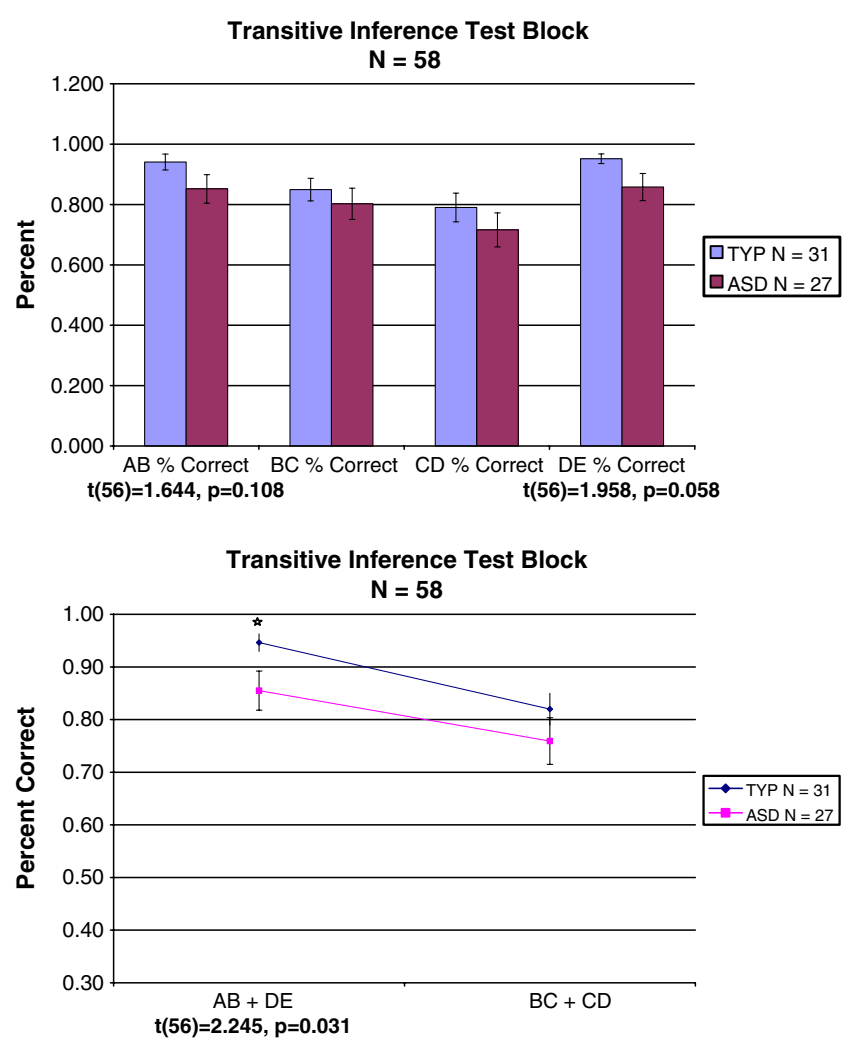

Fig. 4 TI task performance in the test block. Performance of 58 subjects (27 ASDs and 31 TYPs) during the test block of the TI task. The four trial types were grouped into inner (trials "BC" and "CD") and outer (trials "AB" and "DE") pairs. TYPs performed significantly better $(p=.031)$ than ASDs on the outer pairs, but not on inner pairs

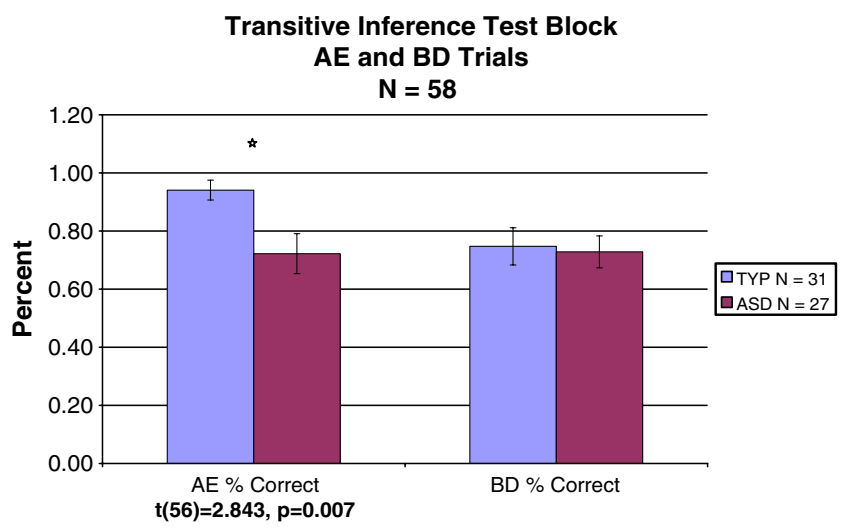

Fig. 5 Test block performance on outer versus inner pairs. Performance of 58 subjects (27 ASDs and 31 TYPs) on novel pairs ("AE" and "BD" trials) during the test block of the TI task. "AE" trials are considered trivial trials because " $\mathrm{A}$ " was always reinforced as being correct during the training blocks, while "E" was always incorrect. "BD"s were reinforced as correct in some situations ("BC" and "DE" trials for "B" and "D," respectively) and as incorrect in other situations ("AB" and "CD" trials for "B" and "D," respectively). Accurately responding to "BD" trials required inferences about the hierarchy. "A" and "B" were the correct responses for "AE" and "BD" trials, respectively. TYPs performed significantly better $(p=.007)$ than ASDs on the "AE," but not on the "BD" pairs our assertion that hippocampal function is at least somewhat intact in ASDs.

The finding of AE impairments is reminiscent of several studies of list, as opposed to stimulus pair, learning that have demonstrated an absence of normal facilitation of learning by beginning and end items in individuals with ASDs (so-called primacy and recency effects; Hermelin \& Frith, 1971; O'Connor \& Hermelin, 1967; Renner, Klinger, \& Klinger, 2000). This pattern also has been found in individuals with dorsolateral PFC lesions (Eslinger \& Grattan, 1994), suggesting that it may be prefrontallymediated. Consistent with this, Renner et al., 2000 argued that their findings about the lack of primacy and recency effects derived from impairments in information organization strategies used by persons with ASDs during memory encoding and retrieval, which are thought to require prefrontal mediation. As was noted earlier, however, several imaging studies have demonstrated that intact hippocampal functioning is required for the development of primacy and recency effects (Axmacher et al., 2009; Strange et al., 2002), challenging the contention that the hippocampus is fully intact. This lack of clarity underscores the need for functional neuroimaging studies of TI that examine the roles of prefrontal and medial temporal brain regions, as well as their functional connectivity.

In addition to participating in rapid updating of reinforcement contingencies and motivational context, the PFC may be required to implement cognitive control through the establishment of a context representation of the task set, and a further explanation for our findings is that impairments in learning end items and the AE pair represent a failure to do so. There are multiple examples that individuals with ASDs do not benefit from the use of contextual information implicitly provided in a task, including findings of increased discrimination of "false memories" (Beversdorf et al., 2000), deficits in learning phonologically and semantically similar word lists versus unrelated ones (B. J. Smith, Gardiner, \& Bowler, 2007), and reduced "memory illusion" for old versus new sentences (Kamio \& Toichi, 2007). In one prominent model of the hierarchy of brain regions implementing cognitive control, representation of the highest conceptual level of a task is thought to rely on the anterior or rostrolateral PFC (Badre, 2008; Badre \& D'Esposito, 2007; Botvinick, 2008; Botvinick, Niv, \& Barto, 2009). In fact, a recent imaging study of TI showed that the rostrolateral PFC was involved in this way (Wendelken \& Bunge, 2009), and our work (Solomon et al., 2009) and that of others suggests that the structure (Zikopoulos \& Barabas, 2010) and function of anterior parts of the PFC may be atypical in ASDs (Dumontheil, Burgess, \& Blakemore, 2008).

Given that interventions premised on learning theory form the mainstay of empirically supported autism treat- 
ments and that generalization deficits are central to learning impairments in individuals with ASDs, it is important to translate findings of experimental learning studies to clinical practice. Our work suggests that simple explicit rule learning is an area of relative strength for individuals with ASDs, but their ability to balance between the use of reinforcement learning that relies on rapidly changing reinforcement contingencies versus more rigid rote strategies may be impaired. This also may influence the relative balance of the different learning strategies they use. During training, they also may benefit less from cues provided by context (such as that given by knowing an item is the beginning or end of a hierarchy) and/or reward-related feedback that implicitly teaches correct choices-a result that is consistent with the few neuroimaging studies of nonsocial (Schmitz et al., 2008) and social (Scott-Van Zeeland et al., 2010) reward processing that suggest impairments in individuals with ASDs. Finally, as has been suggested by computational modelers (i.e., Cohen, 1994; McClelland, 2000), autism may involve "hyperspecific" and excessively conjunctive stimulus representation, making it difficult for neural networks (and the neural systems of learners) to detect and leverage overlaps with other stimuli that would enable the generalization of learning. This would suggest that individuals with ASDs might benefit from explicit training about the commonalities between the many stimuli that lead to similar consequences.

This present study has several limitations. First, in order to improve the homogeneity of our sample and to avoid confounds associated with the use of dopaminergic medications, we recruited only individuals not taking antipsychotics. This decision may limit the generalizability of our results. Similarly, the decision to recruit only high-functioning persons with cognitive abilities in the average range or above, who are now thought to make up over half of all individuals diagnosed with ASDs (Center for Disease Control and Prevention, 2009), means that our findings may not be relevant for individuals with comorbid mental retardation. The sample also included 7 persons taking SSRIs, because asking them to discontinue their medications would violate ethical guidelines for patient-oriented research. Second, although we recruited only individuals without comorbid diagnoses of attention problems, anxiety, or depression, several subjects manifested these symptoms on questionnaires. All analyses were completed without these subjects, and the pattern of findings was identical. Finally, the Frank and Claus (2006) model is premised on dopamine dysregulation, and it is serotonin, and not dopamine, that most frequently is reported to be impaired in autism (Chugani, 2002).

Further limitations of this study are a result of the fact that the hypotheses were derived from two broad, albeit somewhat simplistic, explanations about how TI is achieved. Such explanations focus on the hippocampus, basal ganglia, PFC, and OFC. While functional neuroimaging (fMRI) studies have confirmed that the hippocampus (Greene et al., 2006; Heckers et al., 2004; Zalesak \& Heckers, 2009), the PFC, and the striatum (Acuna et al., 2002; Goel \& Dolan, 2001; Wendelken \& Bunge, 2009) are activated on TI tasks, TI also involves the parietal cortex (Acuna et al., 2002; Greene et al., 2006). Basal ganglia and medial temporal lobe structures also may interact competitively in learning and memory (Frank \& Claus, 2006; Poldrack et al., 2001). Furthermore several recent studies have offered more nuanced insights into the roles of the hippocampus and regions of the PFC in TI that are not contemplated by the two frameworks we employed. The first suggests that the hippocampus, enervated by midbrain dopamine, may be important for the integrative encoding required for inference (Shohamy \& Wagner, 2008), while the second proposes that the ventromedial PFC mediates the online integration and evaluation of associative information conveyed by the hippocampus (Kumaran et al., 2009), as opposed to the basal ganglia. These results offer leads to investigate in future imaging studies and may help clarify the neural and cellular mechanisms underlying our findings and why they deviated from expectations.

In conclusion, although one must exercise caution about inferring changes in neural systems based on behavioral findings, the results of this study illustrate how investigators can utilize computational modeling to generate testable, novel, and constrained hypotheses about the operation of the neural mechanisms and circuits underlying cognitive processes to advance autism research. This is critical since autism is recognized to involve widespread neuropathology across diverse neural circuits, rendering the development of hypotheses difficult and leading to research that is largely descriptive. Then, fMRI can be used to help in adjudicating between explanations of TI involving the roles of brain regions and neural circuits, including the hippocampus and regions of the PFC, in TYP individuals, as well as those with ASDs.

Acknowledgments The authors would like to thank the adults who participated in this study and their family members.

Funding This work was supported by the National Institute of Mental Health (R-01 071847 to A.S., and 1-K-08 MH074967 to M.S.) and Autism Speaks (Pilot Award to M.S.) and NARSAD (Atherton Foundation Award to M.S.).

\section{References}

Acuna, B. D., Eliassen, J. C., Donoghue, J. P., \& Sanes, J. N. (2002). Frontal and parietal lobe activation during transitive inference in humans. Cerebral Cortex, 12, 1312-1321. 
Aizenstein, H. J., Stenger, V. A., Cochran, J., Clark, K., Johnson, M., Nebes, R. D., et al. (2004). Regional brain activation during concurrent implicit and explicit sequence learning. Cerebral Cortex, 14, 199-208.

Amaral, D. G., Schumann, C. M., \& Nordahl, C. W. (2008). Neuroanatomy of autism. Trends in Neurosciences, 31, 137-145.

American Psychiatric Association. (2000). Diagnostic and statistical manual of mental disorders-Revised (4th ed.) (4th ed.). Washington, DC: Author.

Axmacher, N., Elger, C. E., \& Fell, J. (2009). Working memoryrelated hippocampal deactivation interferes with long-term memory formation. Journal of Neuroscience, 29, 1052-1960.

Aylward, E. H., Minshew, N. J., Goldstein, G., Honeycutt, N. A., Augustine, A. M., Yates, K. O., et al. (1999). MRI volumes of amygdala and hippocampus in non-mentally retarded autistic adolescents and adults. Neurology, 53, 2145-2150.

Bachevalier, J., \& Loveland, K. A. (2006). The orbitofrontalamygdala circuit and self-regulation of social-emotional behavior in autism. Neuroscience \& Biobehavioral Reviews, 30, 97-117.

Badre, D. (2008). Cognitive control, hierarchy, and the rostro-caudal organization of the frontal lobes. Trends in Cognitive Sciences, 12, 193-200.

Badre, D., \& D'Esposito, M. (2007). Functional magnetic resonance imaging evidence for a hierarchical organization of the prefrontal cortex. Journal of Cognitive Neuroscience, 19, 2082-2099.

Balleine, B. W., \& Dickinson, A. (1998). Goal-directed instrumental action: Contingency and incentive learning and their cortical substrates. Neuropharmacology, 37, 407-419.

Barnes, K., Howard, J., Howard, D., Gilotty, L., Kenworthy, L., Gaillard, W., et al. (2008). Intact implicit learning of spatial context and temporal sequences in childhood autism spectrum disorder. Neuropsychology, 22, 563-570.

Baron-Cohen, S., Ring, H. A., Bullmore, E. T., Wheelwright, S., Ashwin, C., \& Williams, S. C. (2000). The amygdala theory of autism. Neuroscience and Biobehavioral Reviews, 24, 355364

Bauman, M. L., \& Kemper, T. L. (1996). Observations on the Purkinje cells in the cerebellar vermis in autism. Journal of Neuropathology and Experimental Neurology, 55, 613.

Bauman, M. L., \& Kemper, T. L. (2005). Neuroanatomic observations of the brain in autism: a review and future directions. International Journal of Developmental Neuroscience, 23, 183187.

Bennetto, L., Pennington, B. F., \& Rogers, S. J. (1996). Intact and impaired memory functions in autism. Child Development, 67, $1816-1835$.

Beversdorf, D. Q., Smith, B. W., Crucian, G. P., Anderson, J. M., Keillor, J. M., Barrett, A. M., et al. (2000). Increased discrimination of "false memories" in autism spectrum disorder. Proceedings of the National Academy of Sciences, 97, 87348737.

Botvinick, M. M. (2008). Hierarchical models of behavior and prefrontal function. Trends in Cognitive Sciences, 12, 201-208.

Botvinick, M. M., Niv, Y., \& Barto, A. C. (2009). Hierarchically organized behavior and its neural foundations: A reinforcement learning perspective. Cognition, 113, 262-280.

Boucher, J., \& Lewis, V. (1989). Memory impairments and communication in relatively able autistic children. Journal of Child Psychology and Psychiatry, 30, 99-122.

Bowler, D. M., Gardiner, J. M., \& Grice, S. J. (2000). Episodic memory and remembering in adults with Asperger syndrome. Journal of Autism and Developmental Disorders, 30, 295-304.

Bowler, D. M., Limoges, E., \& Mottron, L. (2009). Different verbal learning strategies in autism spectrum disorder: evidence from the Rey Auditory Verbal Learning Test. Journal of Autism and Developmental Disorders, 39, 910-915.
Bryant, P. E., \& Trabasso, T. (1971). Transitive inferences and memory in young children. Nature, 232, 456-458.

Buckmaster, C. A., Eichenbaum, H., Amaral, D. G., Suzuki, W. A., \& Rapp, P. R. (2004). Entorhinal cortex lesions disrupt the relational organization of memory in monkeys. Journal of Neuroscience, 24, 9811-9825.

Center for Disease Control and Prevention. Prevalence of autism spectrum disorders-Autism and developmental disabilities monitoring network, 14 Sites, United States, 2006. Surveillance summaries, 2009. MMWR 2009; 58 (No. SS-10).

Chugani, D. C. (2002). Role of altered brain serotonin mechanisms in autism. Molecular Psychiatry, 7(Suppl. 2), S16-S17.

Cody, H., Pelphrey, K., \& Piven, J. (2002). Structural and functional magnetic resonance imaging of autism. International Journal of Developmental Neuroscience, 20, 421-438.

Cohen, I. L. (1994). An artificial neural network analogue of learning in autism. Biological Psychiatry, 36, 5-20.

Coleman, M. J., Titone, D., Krastoshevsky, O., Krause, V., Huang, Z., Mendell, N. R., et al. (2010). Reinforcement ambiguity and novelty do not account for transitive inference deficits in schizophrenia. Schizophrenia Bulletin, 36, 1187-1200.

Dapretto, M., Davies, M. S., Pfeifer, J. H., Scott, A. A., Sigman, M., Bookheimer, S. Y., et al. (2006). Understanding emotions in others: Mirror neuron dysfunction in children with autism spectrum disorders. Nature Neuroscience, 9, 28-30.

Daw, N. D., Niv, Y., \& Dayan, P. (2005). Uncertainty-based competition between prefrontal and dorsolateral striatal systems for behavioral control. Nature Neuroscience, 8, 1074-1711.

Dawson, G., Hessl, D., \& Frey, K. (2008). Social influences on early developing biological and behavioral systems related to risk for affective disorder. Development and Psychopathology, 6, 759-779.

Derogatis, L. R. (1994). Symptom checklist-90-R (SCL-90-R): Administration, scoring, and procedures manual (3rd ed.). Minneapolis: National Computer Systems.

Doll, B. B., Jacobs, W. J., Sanfey, A. G., \& Frank, M. J. (2009). Instructional control of reinforcement learning: A behavioral and neurocomputational investigation. Brain Research, 1299, 74-94.

Dumontheil, I., Burgess, P. W., \& Blakemore, S. (2008). Development of rostral prefrontal cortex and cognitive behavior disorders. Developmental Medicine and Child Neurology, 50, 168-181.

Dusek, J. A., \& Eichenbaum, H. (1997). The hippocampus and memory for orderly stimulus relations. Proceedings of the National Academy of Sciences, 94, 7109-7114.

Eichenbaum, H. (2000). A cortical-hippocampal system for declarative memory. Nature Reviews Neuroscience, 1, 41-50.

Eichenbaum, H. (2004). Hippocampus cognitive processes and neural representations that underlie declarative memory. Neuron, 44, $109-120$.

Eichenbaum, H., Yonelinas, A. P., \& Ranganath, C. (2007). The medial temporal lobe and recognition memory. Annual Review of Neuroscience, 30, 123-152.

Ellenbogen, J. M., Hu, P. T., Payne, J. D., Titone, D., \& Walker, M. P. (2007). Human relational memory requires time and sleep. Proceedings of the National Academy of Sciences, 104, 7723-7728.

Eslinger, P. J., \& Grattan, L. M. (1994). Altered serial position learning after frontal lobe lesion. Neuropsychologia, 32, 729-739.

Frank, M. J., \& Claus, E. D. (2006). Anatomy of a decision: Striatoorbitofrontal interactions in reinforcement learning, decision making, and reversal. Psychological Review, 113, 300-326.

Frank, M. J., \& O’Reilly, R. (2006). A mechanistic account of striatal dopamine function in human cognition: Psychopharmacological studies with cabergoline and haloperidol. Behavioral Neuroscience, 120, 497-517.

Frank, M. J., O'Reilly, R., \& Curran, T. (2006). When memory fails, intuition reigns: Midazolam enhances implicit inference in humans. Psychological Science, 17, 700-707. 
Frank, M. J., Rudy, J. W., Levy, W. B., \& O’Reilly, R. (2005). When logic fails: Implicit transitive inference in humans. Memory \& Cognition, 33, 742-750.

Frank, M. J., Rudy, J. W., \& O'Reilly, R. (2003). Transitivity, flexibility, conjunctive representations and the hippocampus: II. A computational analysis. Hippocampus, 13, 341-354.

Frank, M. J., Seeberger, L., \& O'Reilly, R. (2004). By carrot or by stick: Cognitive reinforcement learning in Parkinsonism. Science, 306, 1940-1943.

Girgis, R. R., Minshew, N. J., Melhem, N. M., Nutche, J. J., Keshavan, M. S., \& Hardan, A. Y. (2007). Volumetric alterations of the orbitofrontal cortex in autism. Progress in Neuropsychopharmacology and Biological Psychiatry, 31, 41-45.

Goel, V., \& Dolan, R. J. (2001). Functional neuroanatomy of threeterm relational reasoning. Neuropsychologia, 39, 901-909.

Graybiel, A. M. (2008). Habits, rituals, and the evaluative brain. Annual Review of Neuroscience, 31, 359-387.

Greene, A. J., Gross, W. L., Elsinger, C. L., \& Rao, S. M. (2006). An fMRI analysis of the human hippocampus: inference, context, and task awareness. Journal of Cognitive Neuroscience, 18, 1156-1173.

Hardan, A. Y., Girgis, R. R., Lacerda, A. L., Yorbik, O., Kilpatrick, M., Keshavan, M. S., et al. (2006). Magnetic resonance imaging study of the orbitofrontal cortex in autism. Journal of Child Neurology, 21, 866-871.

Haznedar, M., Buchsbaum, M. S., Hazlett, E. A., LiCalzi, E. M., Cartwright, C., \& Hollander, E. (2006). Volumetric analysis and three-dimensional glucose metabolic mapping of the striatum and thalamus in patients with autism spectrum disorders. American Journal of Psychiatry, 163, 1252-1263.

Haznedar, M., Buchsbaum, M., Wei, T., Hof, P., Cartwright, C., \& Bienstock, C. (2000). Limbic circuitry in patients with autism spectrum disorders studied with positron emission tomography and magnetic resonance imaging. American Journal of Psychiatry, 157, 1994-2001.

Heckers, S., Zalesak, M., Weiss, A. P., Ditman, T., \& Titone, D. (2004). Hippocampal activation during transitive inference in humans. Hippocampus, 14, 153-162.

Hermelin, B., \& Frith, U. (1971). Psychological studies of childhood autism: Can autistic children make sense of what they see and hear? Journal of Special Education, 5, 1107-1117.

Hollander, E., Anagnostou, E., Chaplin, W., Esposito, K., Haznedar, M. M., Licalzi, E., et al. (2005). Striatal volume on magnetic resonance imaging and repetitive behaviors in autism. Biological Psychiatry, 58, 226-232.

Howlin, P. (2003). Outcome in high-functioning adults with autism with and without early language delays: implications for the differentiation between autism and Asperger syndrome. Journal of Autism and Developmental Disorders, 33(1), 3-13.

Jog, M. S., Kubota, Y., Connolly, C. I., Hillegaart, V., \& Graybiel, A. M. (1999). Building neural representations of habits. Science, $286,1745-1749$

Kamio, Y., \& Toichi, M. (2007). Memory illusion in high-functioning autism and Asperger's disorder. Journal of Autism and Developmental Disorders, 37, 867-876.

Kitagawa, G., \& Gersch, W. (1996). Smoothness priors analysis of timeseries: Lecture notes in statistics (Vol. 116). New York: Springer.

Koshino, H., Carpenter, P. A., Minshew, N. J., Cherkassky, V. L., Keller, T. A., \& Just, M. A. (2005). Functional connectivity in a fMRI working memory task in high-functioning autism. NeuroImage, 24, 810-821.

Kumaran, D., Summerfield, J. J., Hassabis, D., \& Maguire, E. A. (2009). Tracking the emergence of conceptual knowledge during human decision making. Neuron, 63, 889-901.

Langen, M., Schnack, H. G., Nederveen, H., Bos, D., Lahuis, B. E., de Jonge, M. V., et al. (2009). Changes in the developmental trajectories of striatum in autism. Biological Psychiatry, 66, 327333.

Lee, P. S., Yerys, B. E., Della Rosa, A., Foss-Feig, J., Barnes, K. A., James, J. D., et al. (2009). Functional connectivity of the inferior frontal cortex changes with age in children with autism spectrum disorders: A fcMRI study of response inhibition. Cerebral Cortex, 19, 1787-1794.

Libben, M., \& Titone, D. (2008). The role of awareness and working memory in human transitive inference. Behavoural Processes, $77,43-54$.

Lord, C., Risi, S., Lambrecht, L., Cook, E. H., Leventhal, B. L., \& DiLavore, P. C. (2000). The Autism Diagnostic Observation Schedule-Generic: A standard measure of social and communication deficits associated with the spectrum of autism. Journal of Autism and Developmental Disorders, 30, 205-223.

Loveland, K. A., Bachevalier, J., Pearson, D. A., \& Lane, D. M. (2008). Fronto-limbic functioning in children and adolescents with and without autism. Neuropsychologia, 46, 49-62.

Luna, B., Minshew, N. J., Garver, B. A., Lazar, N. A., Thulborn, K. R., Eddy, W. F., et al. (2002). Neocortical system abnormalities in autism: An fMRI study of spatial working memory. Neurology, 59, 834-840.

Lunn, D., Thomas, A., Best, N., \& Spiegelhalter, D. (2000). WinBUGS-A Bayesian modelling framework: Concepts, structure, and extensibility. Statistics and Computing, 10, 325-337.

Macintosh, K. E., \& Dissanayake, C. (2004). Annotation: The similarities and differences between autistic disorder and Asperger's disorder: A review of the empirical evidence. Journal of Child Psychology and Psychiatry, 45, 421-434.

McClelland, J. L. (2000). The basis of hyperspecificity in autism: A preliminary suggestion based on properties of neural nets. Journal of Autism and Developmental Disorders, 30, 497-502.

Minshew, N. J., \& Goldstein, G. (1993). Is autism an amnesic disorder? Evidence from the California Verbal Learning Test. Neuropsychology, 7, 209-216.

Moses, S. N., Ostreicher, L. L., \& Ryan, J. D. (2010). Relational framework improves transitive inference across age groups. Psychological Research, 74, 207-218.

Moses, S. N., Villate, C., Binns, M. A., Davidson, P. S. R., \& Ryan, J. D. (2008). Cognitive integrity predicts transitive inference performance bias and success. Neuropsychologia, 46, 1314-1325.

Mostofsky, S. H., Goldberg, M. C., Landa, R. J., \& Denckla, M. B. (2000). Evidence for a deficit in procedural learning in children and adolescents with autism: Implications for cerebellar contribution. Journal of the International Neuropsychological Society, 6. 752-759.

Murphy, K., \& Mahdaviani, M. (2005). MATBUGS software. Retrieved from http://www.cs.ubc.ca/ murphyk/Software/ MATBUGS/matbugs.html.

Nyden, A., Hjelmquist, E., \& Gillberg, C. (2000). Autism spectrum and attention deficit disorders in girls: Some neuropsychological aspects. European Child and Adolescent Psychiatry, 9, 180-185.

O'Connor, N., \& Hermelin, B. (1967). Auditory and visual memory in autistic and normal children. Journal of Mental Deficiency Research, 11, 126-131.

O'Reilly, R. C., \& Rudy, J. W. (2001). Conjunctive representations in learning and memory: Principles of cortical and hippocampal function. Psychological Review, 108, 311-345.

Ozonoff, S., \& Griffith, E. M. (2000). Neuropsychological function and the external validity of Asperger syndrome. In A. Klin, F. R. Volkmar, \& S. S. Sparrow (Eds.), Asperger syndrome (p. 24). New York: Guilford.

Palmen, S. J., Durston, S., Nederveen, H., \& Van Engeland, H. (2006). No evidence for preferential involvement of medial temporal lobe structures in high-functioning autism. Psychological Medicine, $36,827-834$. 
Pelphrey, K. A., Morris, J. P., \& McCarthy, G. (2005). Neural basis of eye gaze processing deficits in autism. Brain, 128, 10381048 .

Pennington, B. F., \& Ozonoff, S. (1996). Executive functions and developmental psychopathology. Journal of Child Psychology and Psychiatry and Allied Disciplines, 37, 51-87.

Piaget, J., \& Inhelder, B. (1956). The child's conception of space. London: Routledge.

Piaget, J., Inhelder, B., \& Szeminska, A. (1960). The child's concept of geometry. New York: Basic Books.

Poldrack, R. A., Clark, J., Paré-Blagoev, E., Shohamy, D., Creso, M. J., Myers, C., et al. (2001). Interactive memory systems in the human brain. Nature, 414, 546-550.

Renner, P., Klinger, L. G., \& Klinger, M. R. (2000). Implicit and explicit memory in autism: Is autism an amnesic disorder? Journal of Autism and Developmental Disorders, 30, 3-14.

Rolls, E. T. (2004). The functions of the orbitofrontal cortex. Brain and Cognition, 55, 11-29.

Salmond, C. H., Ashburner, J., Connelly, A., Friston, K. J., Gadian, D. G., \& Vargha-Khadem, F. (2005). The role of the medial temporal lobe in autistic spectrum disorders. European Journal of Neuroscience, 22, 764-772.

Schmitz, N., Rubia, K., van Amelsvoort, T., Daly, E., Smith, A., \& Murphy, D. G. M. (2008). Neural correlates of reward in autism. British Journal of Psychiatry, 192, 19-24.

Schoenbaum, G., \& Roesch, M. (2005). Orbitofrontal cortex, associative learning, and expectancies. Neuron, 47, 633-636.

Schultz, R. T., Gauthier, I., Klin, A., Fulbright, R. K., Anderson, A. W., Volkmar, F., et al. (2000). Abnormal ventral temporal cortical activity during face discrimination among individuals with autism and Asperger syndrome. Archives of General Psychiatry, 57, 331-340.

Schumann, C. M., Hamstra, J., Goodlin-Jones, B. L., Lotspeich, L. J., Kwon, H., Buonocore, M. H., et al. (2004). The amygdala is enlarged in children but not adolescents with autism; the hippocampus is enlarged at all ages. Journal of Neuroscience, 24, 6392-6401.

Scott-Van Zeeland, A. A., Dapretto, M., Ghahremani, D. G., Poldrack, R. A., \& Bookheimer, S. Y. (2010). Reward processing in autism. Autism Research, 3, 53-67.

Sears, L. L., Vest, C., Mohamed, S., Bailey, J., Ranson, B. J., \& Piven, J. (1999). An MRI study of the basal ganglia in autism. Progress inNeuro-psychopharmacol and Biological Psychiatry, 23, 613624.

Shohamy, D., \& Wagner, A. D. (2008). Integrating memories in the human brain: Hippocampal-midbrain encoding of overlapping events. Neuron, 60, 378-389.

Singer, A. C., \& Frank, L. M. (2009). Rewarded outcomes enhance reactivation of experience in the hippocampus. Neuron, 64, 910 921

Smith, A. C., Frank, L. M., Wirth, S., Yanike, M., Hu, D., Kubota, Y., et al. (2004). Dynamic analysis of learning in behavioral experiments. Journal of Neuroscience, 24, 447-461.

Smith, B. J., Gardiner, J. M., \& Bowler, D. M. (2007a). Deficits in free recall persist in Asperger's syndrome despite training in the use of list-appropriate learning strategies. Journal of Autism and Developmental Disorders, 37, 445-454.

Smith, A. C., Wirth, S., Suzuki, W. A., \& Brown, E. N. (2007b). Bayesian analysis of interleaved learning and response bias in behavioral experiments. Journal of Neurophysiology, 97, 25162524.

Solomon, M., Ozonoff, S. J., Cummings, N., \& Carter, C. S. (2008). Cognitive control in autism spectrum disorders. International Journal of Developmental Neuroscience, 26(2), 239-247.
Solomon, M., Ozonoff, S. J., Ursu, S., Ravizza, S., Cummings, N., Ly, S., et al. (2009). The neural substrates of cognitive control deficits in autism spectrum disorders. Neuropsychologia, 47, $2515-2526$.

Sparks, B. F., Friedman, S. D., Shaw, D. W., Aylward, E. H., Echelard, D., Artru, A. A., et al. (2002). Brain structural abnormalities in young children with autism spectrum disorder. Neurology, 59, 184-192.

Squire, L. R., \& Zola, S. M. (1996). Structure and function of declarative and nondeclarative memory systems. Proceedings of the National Academy of Sciences, 93, 13515-13522.

Stokes, T. F., \& Baer, D. M. (1977). An implicit technology of generalization. Journal of Applied Behavior Analysis, 10, 349-367.

Strange, B. A., Otten, L. J., Josephs, O., Rugg, M. D., \& Dolan, R. J. (2002). Dissociable human perirhinal, hippocampal, and parahippocampal roles during verbal encoding. Journal of Neuroscience, 22, 523-528.

Szatmari, P., Bryson, S. E., Boyle, M. H., Streiner, D. L., \& Duku, E. (2003). Predictors of outcome among high functioning children with autism and Asperger syndrome. Journal of Child Psychology and Psychiatry and Allied Disciplines, 44, 520-528.

Titone, D., Ditman, T., Holzman, P. S., Eichenbaum, H., \& Levy, D. L. (2004). Transitive inference in schizophrenia: Impairments in relational memory organization. Schizophrenia Research, 68, 235-247.

Toichi, M., \& Kamio, Y. (2002). Long-term memory and levels-ofprocessing in autism. Neuropsychologia, 40, 964-969.

Toichi, M., \& Kamio, Y. (2003). Long-term memory in highfunctioning autism: Controversy on episodic memory in autism reconsidered. Journal of Autism and Developmental Disorders, $33,151-161$.

Van der Jeugd, A., Goddyn, H., Laeremans, A., Arckens, L., D’Hooge, R., \& Verguts, T. (2009). Hippocampal involvement in the acquisition of relational associations, but not in the expression of a transitive inference task in mice. Behavioral Neuroscience, 123, 109-114.

Van Elzakker, M., O’Reilly, R. C., \& Rudy, J. W. (2003). Transitivity, flexibility, conjunctive representations, and the hippocampus: I. An empirical analysis. Hippocampus, 13, 334-340.

Vasconcelos, M. (2008). Transitive inference in non-human animals: An empirical and theoretical analysis. Behavioural Processes, 78, 313-334.

von Fersen, L., Wynne, C. D. L., Delius, J. D., \& Staddon, J. E. R. (1991). Transitive inference formation in pigeons. Journal of Experimental Psychology: Animal Behavior Processes, 17, 334341.

Walton, M. E., Behrens, T. E., Buckley, M. J., Rudebeck, P. H., \& Rushworth, M. F. (2010). Separable learning systems in the macaque brain and the role of orbitofrontal cortex in contingent learning. Neuron, 65, 927-939.

Ward, M., Wender, P., \& Reimherr, F. (1993). The Wender Utah Rating Scale: An aid in the retrospective diagnosis of childhood attention deficit hyperactivity disorder. American Journal of Psychology, 150, 885-890.

Wechsler, D. (1999). Wechsler Abbreviated Scale of Intelligence (WASI). San Antonio: Harcourt Assessment.

Wendelken, C., \& Bunge, S. A. (2009). Transitive inference: distinct contributions of rostrolateral prefrontal cortex and the hippocampus. Journal of Cognitive Neuroscience, 22, 837-847.

Zalesak, M., \& Heckers, S. (2009). The role of the hippocampus in transitive inference. Psychiatry Research, 172, 24-30.

Zikopoulos, B., \& Barbas, H. (2010). Changes in prefrontal axons may disrupt the network in autism. Journal of Neuroscience, 30, 14595-14609. 